\title{
Study on Increase of Undergraduates Entrepreneurship Rate by Comparing Entrepreneurial Environments between China and America
}

\author{
Zhong-Tong LIU ${ }^{\text {a }}$, Kai Wang ${ }^{\text {* }}$ \\ Beihua University, Jilin, China \\ a z13140oy@163.com , b178971787@qq.com \\ ${ }^{*}$ Corresponding author Kai Wang
}

Keywords: undergraduates' entrepreneurship, entrepreneurial environment, between China and America

\begin{abstract}
The entrepreneurial education of our country is still at its starting stage, so there are some deficiencies in parts of training objectives, training modes and practice. This paper specifically propounds suggestions upon increasing undergraduates' entrepreneurship rate and success rate by the comparison between entrepreneurial environment of China and that of America.
\end{abstract}

\section{Introduction}

"Employment difficulty” for college graduates has been an issue that we can not turn a blind eye to, entrepreneurship becomes an effective method to solve this current situation, and it can not only create wealth but also shoulder more social responsibilities. Under this general environment, the undergraduates of our country get self-employment stared, but still in an immature stage. Compared with western countries, Chinese undergraduates' entrepreneurship rate and success rate are lower. For instance, the proportion of American undergraduates' entrepreneurship rate is up to 20-23\%, while in China, based on some statistics, the rate is less than $1 \%$.

As educators, it is imperative to absorb the foreign mature entrepreneurial culture concept and simultaneously to develop college students' entrepreneurship education and increase entrepreneurship rate and success rate according to the China's actual situation

\section{The current development situation of American undergraduates' entrepreneurial environment}

American undergraduates' entrepreneurship is very common. In addition to Bill Gates who is well-known to everybody, Dell of Dell Computer Company Started his own company at the age of 19 and finally succeeded. Anyone's career success depends on both subjective and objective conditions.

1. From the subjective conditions, American undergraduates have the following characteristics:

1.1 Individualism is ingrained in minds of Americans. Although this kind of individualism has some social disadvantages, it has its significance of reasonable existence from the entrepreneurial point of view. This kind of individualism makes people dare to innovate and struggle.

1.2 The open educational system pursues personality development and strong manipulative ability. From school to family, free cultivation is adopted, which increases students' independent abilities and cultivates energy of daring to think and daring to do, and this kind of educational system makes students' personalities open and flexible and practical ability strong. Generally they will manage to reach economic independence after 18 years old.

2. From social factors, America has many advantages to support entrepreneurship.

2.1 The social atmosphere formed by coexistence of encouragement and tolerance as is one of the favorable conditions for entrepreneurship. America does not have a long history, but it has the most developed economy, which can not be isolated from other countries. In American society, personal struggle is advocated. This make America form an atmosphere of encouraging innovation, which encourages a lot of entrepreneurs to be engaged in starting business. In America, personal 
entrepreneurship is an honorable stuff. What's more, at the same time when entrepreneurship is encouraged, the failure of it is also tolerated. With the protection of business insurance system, the business failures will get some compensation, this kind of policy makes entrepreneurs concentrated on starting business without scruple.

2.2 Convenient conditions and systems are the advantages to support entrepreneurship. In America, the process of opening a company is very convenient. Low entry requirement, simple application process and wholesome credit system are beneficial to new companies' opening and operation. Depending on the developed network economy platform, trading and lending are both convenient.

2.3 The free flow of talent and flexible employment mechanism are the favorable conditions for entrepreneurship. The entry and exit of human resources in America is quite flexible, whatever the career is, it has the freedom. Procedure of dropping out of school and continuing to learn for undergraduates is handy, and as long as your credits are full, you can graduate. This kind of freedom and flexibility makes entrepreneurs free from worries.

2.4 Strong VC (venture capital) funds and mature GEM (growth enterprise market ) provides favorable conditions for entrepreneurs. After World War II, economic growth in the United States sustained for decades, a lot of social wealth was accumulated, and abundant capital was possessed by folk. In order to make their cash hedged, quite a number of private funds are used as venture capital, looking for the developing projects and companies and then injecting new funds to let them go to market, so as to obtain high returns. Mature growth enterprise market surely becomes an effective channel to get rich quickly for the founders, and also provides the perfect investment-exiting service to investors, this kind of environment will undoubtedly promote the boom of social entrepreneurship in the United States.

2.5 Research suggests that national economic growth of small and medium-sized enterprises in the United States is greater than that of the big enterprise, and they create a large proportion of jobs, small businesses in the United States usually refer to the enterprises whose employees are within five hundred in number. According to the official statistics, more than 99\% of U.S. Companies are small businesses, which give as much as $75 \%$ of the new job offers. This status recognition shows that the whole American society is encouraging and supporting the establishment of small and medium-sized enterprises.

Based on a combination of the above conditions, the high success rate of entrepreneurship has been created. From a respective analysis of the above aspects, it is not difficult for us to see that these conditions are in mutual promotion. The sustainable development of this relevance will finally lead entrepreneurship in the United States to an escalating trend.

\section{The current situation of undergraduates' entrepreneurial environment}

Today our country is in a transition point of economic and social development. Traditional thinking changing and positive innovation have become an important task in today's colleges and universities. The improvement of college students' practical ability and comprehensive quality as well as the change of inherent thinking under the exam-oriented education require long-time hard work. Therefore, Chinese college students' entrepreneurship is still under a lot of tests.

1. The incomplete undergraduates' entrepreneurship policy of our country increases the difficulty of undergraduates' entrepreneurship.

The present entrepreneurship policy and system for college students in our country is not yet mature, in the core period of national system transformation, the problems of attending to one but losing another often arise, in this period entrepreneurship is at an increasing risk. College students in our country do not form the body of the entrepreneurship army, so there are no more special policies given to college students. Industry, commerce and taxation have no greatly preferential policies, neither do the enterprise system and financial system. This current situation makes undergraduates and entrepreneurs in society would like to venture and struggle in the same road, it is difficult to succeed. 
2. College students' incomprehension of entrepreneurship policy influences their entrepreneurial passion

According to the survey, only 5.3\% of college students know well about the government's entrepreneurship policy, $43 \%$ of college students know a little about the entrepreneurship policy, and $51.4 \%$ of college students do not know the entrepreneurship policy at all; $3.2 \%$ of college students know well about the loan policy for undergraduates' entrepreneurship, $29.6 \%$ of college students know a little, and $65.8 \%$ of college students don't know anything about it. The survey results show that from the government to the colleges and universities in our country, the propaganda for the relevant policies of the college students' entrepreneurship is not enough. The incomprehension of policies makes college students shrink back at the sight of entrepreneurship.

3. Undergraduates' entrepreneurship is short of financial support

Today, in the primary stage of socialism, Chinese family incomes can not support the venture capital expenditure of an entrepreneurial project, college students from remote or rural areas even worry about clothing and food, it is impossible for them to to raise venture capital only relying on their family and social relationships. At the same time, affected by the traditional family education concept, college students of our country lack of economic independent consciousness compared with those of developed countries. In addition, the venture capital of our country is far from abundance, it is still in its infancy, the difficulty of financing has made many college students only have a heart of entrepreneurship but without practical use.

4. Undergraduates' entrepreneurship is short of entrepreneurial education and training support

Entrepreneurship requires entrepreneurs to have rich knowledge and experience of management, be ready for each change at any time, and know about the general circumstances and policies. This knowledge needs long-term learning and accumulation. Because entrepreneurship education in our country is still in its early stage, there are few colleges and universities strengthen the attention to entrepreneurship education, let alone lead entrepreneurship education into the formal credit system. And today market economic system is not perfect in our country, campus environment is dramatically different from social environment, it is difficult to adapt to the business environment for the students who just step out of campus. Lack of entrepreneurial education that is the essential reason for resulting in low undergraduates' entrepreneurship rate and success rate in our country.

From the comparison between entrepreneurial environments of China and the United States, we will find that in terms of entrepreneurial environment, college students in China have a bigger disparity compared with American college students. This disparity includes their own quality and ideas, social cultural atmosphere, economic system and policy environment, etc. So if you want to change the current situation of undergraduates' entrepreneurship rate and success rate of our country, a long-term and systematic project will be needed.

\section{The enlightenment from the comparison between entrepreneurial environments of China and the United States}

Whether there is a comprehensive and three-dimensional entrepreneurial supporting system is one of the keys to the success of college students' entrepreneurship, from society to the government and to universities, a variety of ways should be simultaneously adopted to promote and perfect the entrepreneurial supporting system for college students.

1. A variety of ways should be simultaneously adopted to create a social cultural atmosphere beneficial to entrepreneurship

Compared with the universities of western developed countries, entrepreneurship education in colleges and universities of our country started later, resulting that the overall entrepreneurial atmosphere is not thick, it requires not only the attention of colleges and universities, but also a positive guidance of the whole society. We have mentioned above that the entrepreneurs in the United States are greatly respected, entrepreneurs will also intend to play down business difficulties when in experience introductions , they give the following entrepreneurs more positive guidance, and encourage people to overcome difficulties. While in China when we heard some university graduates 
are engaged in infrastructure services or agriculture, etc., we will come up with different views, which generates invisible discrimination for entrepreneurs' industries. Therefore the whole society should form a correct attitude toward the understanding of entrepreneurship , so that entrepreneurial atmosphere will get better. This shift in attitude needs a long-term process, and the correct guidance of the government is especially important.

2. Reform and innovate, establish a flexible and practical entrepreneurship education supporting system

Entrepreneurship is an activity full of distinct personalities, only when the autonomy and initiative of students are stimulated can the growth of entrepreneurial talents be promoted, it requires a liberal, open and progressive learning environment. Colleges and universities should fully realize it, and know that entrepreneurship education does not depend on the boring entrepreneurship courses when promoting entrepreneurship education in an all-round way, but depend on flexible and changeable entrepreneurship practice activities, so more entrepreneurial activities and competition should be organized to improve the entrepreneurship ability of college students. In addition, entrepreneurship education should have different focuses in different phases of education. Freshmen focus on the enlightenment of their entrepreneurial awareness, sophomores focus on the cultivation of entrepreneurship ability, juniors and seniors focus on entrepreneurial practice knowledge, and even entrepreneurial practice if condition allows.

3. Enhancement of the government policy supports and universities' policy preaching efforts

Government policy is an important part of college students' entrepreneurial supporting system, local governments have successively introduced their respective entrepreneurial supporting policies for college students, in the policies, it is top priority to solve the problems of college students' venture capital support. Policies in detail may include lowering the commercial banks' requirements of small business loan for college students, intensifying supervision of the commercial bank loans, and effectively improving the lending rate of commercial banks on college student entrepreneurs. At the same time when government gives corresponding policies, colleges and universities must convey the relevant policies timely to the students with entrepreneurial ideas, so as to effectively guarantee the use of resources.

\section{Acknowledgements}

This research was financially supported by the "13th Five-Year" project planning of the Scientific and Technological Research Project of Department of Education of Jilin Province in 2016, China (Grant No. GH16071).

\section{References}

[1] Zhang Fan: A comparative analysis of the entrepreneurial environment of Chinese and American College Students [J]. Scientific Management Research, 2010 (1)

[2] Xu Guangyong: Comparison and Enlightenment of Chinese and American College Students' entrepreneurial practice ability training [J]. Educational Review2016 (3)

[3] Wang Baoyi : The research and Enlightenment of university students' Entrepreneurship Education in western countries [J]. Theory and Practice of Education, 2011 (5)

[4] Liu Ping、Zhou Juan: Characteristics of entrepreneurship education in American universities and Its Enlightenment to China [J]. Adult Education, 2011（12）

[5] Pang Bo: Comparison of entrepreneurship education between Chinese and American College Students $[\mathrm{M}] .2008$

[6] Lin Lei: Comparative study on Entrepreneurship Education between Chinese and American students [J]. Ideological \& Theoretical Education, 2012 (17) 